\title{
JUVENTUD, DELINCUENCIA Y VIOLENCIA
}

\section{(Ponencia - ampliada y revisada - presentada al Segundo Congreso Nacional de Investigadores Sociales y Médico-sociales sobre Juventud Chilena)}

Autor: Doris Cooper Mayr. Director Soc. Chilena de Criminología, Psiquiatría Social y Criminalística; Director Sociedad Chilena de Sexología y Ed. Sexual. Docente Universidad de Chile, Instituto Profesional de Santiago, Universidad La República. Miembro ISA y del Research Committee for the Sociology of Deviance and Social Control.

\section{ANTECEDENTES}

\section{Investigaciones Realizadas}

El Paper se fundamenta en cuatro Investigaciones empíricas realizadas por la autora y terminadas en Marzo 1992, patrocinadas por la Universidad de Chile, Gendarmería de Chile y una de ellas por CONICYT. Estas son las siguientes:

1) "Teoría del Continuo Subcultural de la Delincuencia: aspectos Subculturales y Psicosociales asociados".

2) "Actitudes de los Condenados hacia la Rehabilitación".

3) "Los Disciplinarios".

4) "Comportamiento Sexual Intrapenitenciario".

\section{PLANTEAMIENTO GENERAL DEL PROBLEMA}

El conjunto de estas Investigaciones, de carácter complementario a otras desarrolladas durante los años 1983 a 1988, intentan describir las principales características de la Delincuencia Común en Chile y en Santiago, dada la carencia de antecedentes empíricos de amplia cobertura respecto de este Problema Social y el creciente interés actual que reviste a nivel gubernamental y ciudadano.

Hasta 1983, se concibe y describe la Delincuencia en Chile como un fenómeno de carácter homogéneo, distribuido al azar y sin diferencias tipológicas. Sin embargo a partir de una primera investigación exploratoria y posteriormente mediante la realización de un Survey de carácter Cross National Research en 1983, se verifica empíricamente la existencia de cinco Tipos de Delincuencia.

Desde esta perspectiva, las Investigaciones realizadas intentan aportar un conjunto de conocimientos respecto de la realidad delictual, con el fin de contribuir a la revisión de Políticas y Programas de Rehabilitación y Prevención de la Delincuencia de carácter diferencial.

Las investigaciones describen aspectos criminológicos, demográficos, antropológicos, económicos, sociológicos y psicosociales de los cinco típos de delincuencia empíricos y diferenciales existentes en nuestro país, utilizando una perspectiva de carácter interdisciplinario.

Se profundiza además particularmente en la problemática de la Contracultura Delictual, la Rehabilitación, Comportamientos Sexuales intrapenitenciarios y aspectos psicosociales, y subculturales etiológicos asociados, así como en los comportamientos desviados, relativos a la drogadicción y alcoholismo.

En síntesis se intenta aportar con una descripción general y específica en determinados niveles de análisis diferenciales, así como con una perspectiva etiológica respecto de las variaciones 
Tipológicas de la conducta delictual social, con el fin de entregar antecedentes empíricos y teóricos referentes a la Delincuencia Común y de Clase Baja en Chile.

\section{OBJETIVOS GENERALES:}

3.1. Describir las características sociodemográficas, subculturales, contraculturales, económicas y psicosociales del Comportamiento Delictual Común Diferencial en Chile y en Santiago.

3.2. Describir la relevancia de la Delincuencia Juvenil en Chile así como sus principales características.

3.3. Analizar elementos etiológicos asociados al Comportamiento Delictual en Chile.

3.4. Describir y Analizar los procesos de Rehabilitación existentes.

3.5. Describir y analizar el Comportamiento Sexual Intrapenitenciario.

\section{RELEVANCIA PRÁCTICA, TEÓRICA Y METODOLÓGICA}

\subsection{Relevancia Práctica:}

La relevancia Práctica de estos estudios consiste en el aporte al conocimiento de las principales características que asumen los diferentes Tipos de Delincuencia Común en Chile. De esta forma, se contribuye a la posibilidad de generar un proceso de revisión o reformulación de las actuales Políticas de Prevención y de Rehabilitación de la Delincuencia, imperantes en el país.

Se posibilita además, en caso de ser necesario, la génesis de nuevas Políticas y Programas en este campo, que propendan a implementaciones racionales basadas en la empiria y en proposiciones teóricas nacionales referentes al problema de la Delincuencia en Chile.

\subsection{Relevancia Teórica:}

Estas investigaciones, basadas en la Teoría del Continuo Subcultural de la Delincuencia, desarrollada por la autora en 1990, permitieron a verificar un nuevo conjunto de hipótesis complementarias a la proposición teórica inicial y en este sentido, posibilitaron su ampliación en otros niveles de análisis, no verificados en una primera aproximación.

Desde esta perspectiva, los estudios contribuyen a ampliar y precisar planteamientos teóricos nacionales criminológicos.

\subsection{Relevancia Metodológica:}

1) Se contribuye con la elaboración de un conjunto de escalas de carácter psicosocial en el ámbito de las Percepciones, Motivaciones y Actitudes. 2) Se clabora una Entrevista que comprende ítems cerrados y abiertos específicamente desarrollada para personas rotuladas como Delincuentes. 3) Se desarrolla una aproximación cualitativa desde la perspectiva etnometodológica, que incluye la opinión de los actores sobre las construcciones de segundo orden objetivizadas en 3 Teorías Criminológicas Metropolitanas.

\section{MARCO TEÓRICO}

Se utiliza un conjunto de Paradigmas y Teorías en términos deductivos-integrativos en el marco de la "Teoría del Continuo Subcultural de la Delincuencia", Teoría elaborada por la autora y presentada al Congreso Mundial de Sociología 1990.

Las Teorías utilizadas son desde una perspectiva sociologica, la Teoría de la Anomie y Anomia de R. Merton, Srole, etc.; La Teoría de la Asociación Diferencial de E. Sutherland; Teoría 
de Sykes; la Teoría de los Gluecks; En el marco de la Antropología, la Teoría de la Marginalidad, de las Estructuras Transicionales, del Prejuicio; Desde una perspectiva económico-social, la Teoría del Desarrollo y muy particularmente, la Teoría de la Dependencia así como también la proposición de la existencia de una Economía Contracultural Redistributiva Violenta; Desde un ángulo psicosocial, la Teoría del Modernismo Actitudinal, las Percepciones Sociales, Actitudes, Valores, Atribuciones de Causalidad y Motivaciones integradas a la Teoría del Continuo Subcultural de la Delincuencia; Finalmente incorporamos el Interaccionismo Simbólico, la Etnometodología y la Teoría del Conflicto.

La Teoría del Continuo Subcultural de la Delincuencia integra las Teorías de Merton, Sutherland, Sykes y Gluecks anteriormente mencionadas, para explicar exclusivamente algunas dimensiones la Delincuencia Masculina Urbana.

La Teoría del Desarrollo y la Teoría de la Dependencia se constituyen en Paradigmas de relevancia en el campo de la Criminología, en la medida que nos orientaron en la construcción tipológica elaborada particularmente en cuanto a la predicción de la ex istencia empírica de Tipos Diferenciales de Delincuencia existentes en áreas ecológicas con grados de desarrollo infraestructural diferenciales en el contex to de nuestro país y en general, del mundo capitalista complementario y dependiente del metropolitano.

De esta forma, fue posible detectar dos Tipos generales de Delincuencia (que comprenden los cinco tipos específicos de Delincuencia mencionados): un Tipo de Delincuencia Moderno y un Tipo de Delincuencia Tradicional, asociadas a áreas ecológicas relativamente desarrolladas y a áreas ecológicas tradicionales en el marco de las economías de autosubsistencia, respectivamente.

La Teoría del Continuo Subcultural de la Delincuencia utiliza además las Teorías Antropologicas mencionadas anteriormente para indagar en la problemática delictual del Migrante Rural-Urbano y de la Delincuencia Indígena.

Las Teorías Psicosociales son incorporadas para develar los aspectos Perceptivos, Motivacionales y Actitudinales diferenciales existentes en los actores sociales representativos de los cinco Tipos de Delincuencia.

El Interaccionismo Simbólico nos permitió indagar en aspectos de relevancia central, asociados a la autopercepción y a la percepción social de la sociedad desde la perspectiva contracultural y entre otros aspectos, conocer la Economía Contracultural Redistributiva, los roles laborales de los ladrones, el Código Ético y Penal de la Contracultura Delictual Urbana, etc. Por otra parte, se analizó en el marco de este paradigma tanto el área temática de la Rotulación como la existencia de valores subterráneos.

Finalmente, el Paradigma Etnometodológico, fue utilizado fundamentalmente para conocer, desde una perspectiva cualitativa, la realidad fenomenológica de los actores sociales involucrados y la construcción social de la realidad a partir de esta perspectiva perceptual primaria.

La explicación de la conducta delictual formulada por los propios actores, involucró la posibilidad de conocer y describir un conjunto de procesos motivacionales diferenciales y de radical importancia, asociados a los distintos Tipos de Delincuencia. Por otra parte, permitió exponer a la crítica explicativa de los actores, un conjunto de tres construcciones de segundo orden correspondientes a tres clásicas teorías criminológicas metropolitanas y obtener de esta forma una medida analítica del grado de concordancia de la explicación teórica y la explicación de los actores involucrados en la Delincuencia.

En este sentido, se integra diferencialmente la perspectiva Etnometodológica con amplia cobertura no solamente en cuanto a sus implicaciones metodológicas cualitativas sino fundamentalmente en cuanto a la consideración radical del actor social y sus perspectivas de percepción 
social ideológico-subcultural y contracultural e interpretaciones explicativas de la realidad cotidiana de clase baja marginal.

Por último, la Teoría del Conflicto ya implícita en el marco de la Teoría de la Dependencia, permite reflexionar teóricamente acerca de la sobrerrepresentación de la clase baja, la extrema pobreza (lumpenproletariado) y marginalidad del sistema, de los actores involucrados en la problemática de la Delincuencia Común, así como respecto de los Tipos Diferenciales de Delincuencia existentes en el mundo desarrollado y el complemento tercer mundista.

\section{MARCO METODOLÓGICO}

Se realizan 4 Surveys tipo Cross National Research, en dos Regiones: Región Metropolitana y Región de la Araucanía, ambas representativas, en determinadas áreas ecológicas, de los polos más relativamente desarrollados y tradicionales del sistema, respectivamente.

Se recorren un total de 22 Unidades Penales, se analizan 3900 casos, se entrevista personalmente a 640 Condenados, controlando pertenencia ecológica, migraciones, sexo y etnia y se recogen Datos Primarios y Secundarios legales.

Se utiliza una Entrevista con ítems cerrados y abiertos, un estudio cualitativo tipo Etnometodológico y 10 Escalas, siete de las cuales han sido elaboradas por la autora.

Se estudian dos subuniversos (el Universo Rural Mapuche y no Mapuche) y se utiliza un muestreo aleatorio estratificado en la Región Metropolitana, conformado según sexo, etnia y pertenencia ecológica en una primera aproximación y en segundo lugar, en función de los Tipos atípicos-especílicos de Delincuencia asociada a Homicidios y Delitos Sexuales existentes en las grandes Urbes.

Las Investigaciones se realizan entre enero 1989 y noviembre de 1991. Se trata de Surveys ex-post-facto, de corte transversal y el análisis de los datos comprende además un estudio comparativo respecto de surveys realizados anteriormente en las mismas Regiones entre los años 1983 y 1988.

De esta forma, estas cuatro Investigaciones son estudios complementarios ampliados en términos de profundización, en cuanto al Planteamiento del Problema, al Marco Teórico y al Marco Metodológico respecto de las Investigaciones Criminológicas realizadas entre 1983 y 1988 en cinco Regiones del país.

\section{CONCLUSIONES GENERALES}

En Chile, se distinguen al menos 5 Tipos Diferenciales de Delincuencia Común, en el marco de la Clase Baja y la Extrema Pobreza: 1) Un Tipo de Delincuencia Masculina Urbana extrema; 2) Un Tipo de Delincuencia Masculina Rural Mapuche; 3) Un Tipo de Delincuencia Masculina Rural no mapuche; 4) Un Tipo de Delincuencia Femenina Urbana; 5) Un Tipo de Delincuencia Femenina Rural.

Cada uno de estos Tipos de Delincuencia tiene características cuantitativas y cualitativas específicas, con diferencias estadísticamente significativas, diferencias que describimos y explicamos en el contex to de la Teoría del Continuo Subcultural de la Delincuencia.

Éstas sustentan en térıninos absolutamente sintéticos las siguientes características criminologicas:

1) La Delincuencia Masculina Urbana Extrema se asocia a las grandes urbes industriales y comerciales y se caracteriza por concentrar en la actualidad un $90 \%$ de Delitos contra la Propiedad. Presentan una alta Reincidencia y Habitualidad Delictual comparativa. Este Tipo de 


\section{REVISTA DE SOCIOLOGÍA}

de mayor incremento de la Población Penal es de 1982 a 1989, elemento que consideramos directamente relacionado a un desarrollo económico con altísimo costo social y a las consecuencias de la crisis económica de 1982 (Cooper D. 1992).

La Violencia Delictual es efectivamente mayor en las urbes en la actualidad. Los Robos con Violencia y los Robos con Intimidación que alcanzaban la cifra de un 31\% en 1983, en 1991 representan un 56\%. Si sumamos a esta cifra los Robos con Homicidio, los Robos con Violación, se alcanza a un 67\% del total de los Delitos Urbanos ( Santiago - 1991).

Del total de estos Delitos, de robos un $59 \%$ son "Cogoteos" y un $41 \%$ son Asaltos, predominantemente a Taxistas y a Domicilios habitados y en segundo término a botillerías, almacenes, fábricas, terminales de micros, servicentros, etcétera.

La Delincuencia Urbana es eminentemente joven: un 30.5\% de ellos son jóvenes de 18-24 años y $36.9 \%$ son adultos jóvenes de $24-29$ años, lo que suma un total de $67 \%$. La mayor parte de ellos pertenece al Estrato Bajo (86.8\% considerando el estrato de origen en el caso de los refractarios laborales normativos y $90 \%$ si consideramos a los Ladrones en el Estrato inferior de el Instrumento Rogers-Sepúlveda), y el complemento que corresponde a obreros especializados, etc. Sólo un $2.5 \%$ pertenence a la clase media baja o media. En general son solteros y poseen bajísimos niveles educacionales.

El $81.3 \%$ de ellos consume habitualmente mezclas de hasta cinco componentes de psicotrópicos como alcohol, marihuana y fármacos y en un bajo porcentaje de casos, cocaína, base, hachis, bencina, peyote, etcétera.

La Delincuencia Juvenil Urbana se expresa en dos Tipos principales: una Delincuencia potencialmente Profesional (se encuentran haciendo "la carrera de Ladrones") o Profesional, enmarcada en la Contracultura Delictual y el Hampa, y una Delincuencia no Profesional constituida por los "Choros de Esquina" o Pandillas de Poblaciones Marginales, que no constituyen una contracultura delictual propiamente tal sino que se enmarcan en la objetivación de formas de conducta desviada de la normativa.

Este último Tipo de Delincuencia se caracteriza por ser ocasional pero extremadamente violenta, dado que suele realizarse bajo los efectos de pisocotrópicos. Entre los Delitos predominantes figuran los Asaltos a Taxistas y a Domicilios habitados, resultando muchos de estos casos agravados por la comisión conjunta de Delitos de Homicidio o Violación.

Entre las principales motivaciones de este tipo de Robos se encuentran las siguientes: "Para los vicios"; "Por necesidad y Droga"; "Para Jarana"; "Para Bacilar"; "Para divertirme"; "Para hacerme ver"; "Para vestirme"; "Por falta de Educación y Necesidad".

Este tipo de Delitos de Robos con Homicidio o de Robos con Violación, son fuertemente rechazados por el hampa profesional, quienes sustentan como valor dentro del Código ético contracultural, el "no hacer daño" en forma innecesaria, salvo peligro de pérdida de libertad o muerte inminente para ellos o sus compañeros. El hampa profesional señala sentirse profundamente preocupada por estos hechos que los desprestigian frente a la opinión pública y los agentes de control social.

El Efecto Demostración, la búsqueda de status virtuales alternativos y de válvulas de escape frente a situaciones de no participación y marginación ecológica y socioeconómica generan en los jóvenes marginales rotulados de "Choros de esquina" autoagresión y violencia que no sólo preocupan al Gobierno y a la ciudadanía, sino incluso, como se ha señalado, al Hampa.

La búsqueda de Status virtuales de clase media o media alta, se objetiviza en el uso de ropas de marcas que simbolizan la adscripción a un status socioeconómico de referencia magnificado por los medios como de logro social conjuntamente, la violencia asociada a la pertenencia a una clase social sin oportunidades en el ámbito de la deseperanza aprendida, decanta en una autoagre- 
sión objetivizada en una altísima ingestión de drogas enmarcada en "ritos de posesión" fundamentalmente grupales.

La ausencia en el marco de la percepción social generalizada actual, de utopías asequibles y de canales políticos abiertos de participación cultural y societal, incrementan la búsqueda de válvulas de escape insertas en los mesianismos (predominantemente entre los adultos) y los ritos de posesión (entre los jovenes) para quienes son marginales extremos y no tienen otras alternativas inmediatas. La ausencia en el marco de la ideología predominante de utopías viables y próximas subrayada por los medios, potencia la deseperanza aprendida.

El ámbito del sistema contracultural del Hampa en cambio, se manifiesta en términos absolutamente distintos y disruptivos respecto del stablishment. Son marginales pero además son marginales contestatarios-críticos, aunque evidentemente sin una proposición política. Rechazan el sistema normativo y se insertan en una estructura cultural alternativa correspondiente a una estructura económica redistributiva contracultural.

Los adultos y jovenes Delincuentes Profesionales, sustentan un Código Ético contracultural, un Código Penal alternativo, un Lenguaje particular (Coha), y se insertan en una escala de Estratificación Social Contraculural que comprende 9 Estratos muy bien delimitados. Esta Estratificación Social alternativa contracultural se conforma en base a estratos delimitados según sea el status de prestigio asignado y socialmente percibido de el rol "laboral" que cumplen en el marco de la Economía Redistributiva contracultural delictual del Delito Económico de la Clase Baja.

El prestigio contracultural socialmente asignado y socialmente percibido se delimita en función de los roles laborales específicos, grados de especialización y habilidad requerida, ingresos, así como también y especialmente por el cumplimiento estricto del Código Ético contracultural.

Los roles laborales de los Ladrones-Ladrones (como se autodefinen y autoperciben) implican horarios, localidades ecológicas específicas de trabajo, días regulares de trabajo a la semana, compañeros laborales, utilización de ropas adecuadas (uniformes laborales que permiten "pasar piola"), pago de "el apunte", "la parte", o la "salvá de pelo", y repartición de las utilidades entre los compañeros, si el trabajo requiere de dos o más participantes. Si "el compañero" o "machucao" transgrede el Código Ético y "hace la bicicleta o tira pal monte" (apropiándose de dinero o especies inequitativamente), será sancionado por el Hampa, en el marco de su Código Penal.

El rol laboral de Ladrón conlleva un riesgo, al igual que todo rol laboral y en este caso la pérdida de la libertad o de la vida, son riesgos asumidos por el profesional. De esta forma la rigurización del Código Penal normativo, incluida la revisión de la aplicación de la pena de muerte (propuesta por algunos representantes de Partidos Políticos), carecen de sentido en el ámbito del ladrón profesional. Enfrentan la muerte cotidianamente.

La mayor parte de los Ladrones proviene de la extrema pobreza y comienzan a participar en actividades delictivas predominantemente entre los 8 y 12 años, siendo la edad inferior límite, de 6 años. En consecuencia la rebaja de la imputabilidad penal a 14 años, tampoco constituye una solución, sino tan sólo conforma la expresión elitista de una Represión del menor marginado y que atenta contra los Derechos del Niño. La Represión no incide en la etiología de la extrema pobreza ni en sus consecuencias.

Los roles laborales constituyen, al igual que en la sociedad normativa, Estratos Sociales diferenciales en el marco de la Clase Baja. En Chile carecemos de Mafia (de carácter eminentemente metropolitano salvo sus expresiones recientes en el Tráfico) a nivel de la Delincuencia Común, la que se constituye comparativamcnic en el tercer mundo y en nuestro país, en unia Delincuencia subdesarrollada. 
Estos estratos en orden decreciente de prestigio están consituidos por:

1) Los Asaltantes (generalmente de sevicentros, terminales de micros, almacenes, farmacias, etc.). Sólo un 1,8\% de ellos han asaltado Bancos alguna vez en el lapso de su vida delictual. 2) Los Internacionales (Ladrones que trabajan en áreas metropolitanas "ganan en dólares" e invierten en nuestro país); 3) Los Monreros (Ladrones de casas o fábricas); 4) Los Lanzas (entre los que destacan los que "andan de mano", los a chorro o escaperos, y los "montados"); 5) Los que andan de Toco (roban autos completos o implementos automovilísticos); 6) Los Mecheros (que hurtan en tiendas utilizando fajas clasticadas en el cuerpo); 7) Los que trabajan el Descuido (en terminales de buses, trenes, aeropuertos, etc., distrayendo la víctima); 8) Los Cuenteros; 9) Los Cogoteros (que ocupan el estrato más bajo especialmente si cogotean a personas de clase baja);

Los Ocasionales y los Choros de Esquina, no constituyen parte del Hampa profesional. Los ocasionales corresponden a obreros que ocasionalmente roban y que se autoperciben como trabajadores. Estos robos ocasionales son consecuencia necesaria, según ellos de los bajos salarios, "que apenas alcanzan para pagar una pieza, comprar pan y pagar la micro".

En relación al Código Ético, encontramos un conjunto de valores de relevancia, entre los que destacan en términos de Escala de Valores los siguientes: 1) Ser Ladrón-Ladrón. Ser Ladrón-Ladrón implica autopercibirse como Ladrón, sentirse profundamente orgulloso de ser percibido así por el hampa, en lo posible tener "cartel" (alta cuota de prestigio) y vivir exclusivamente del robo, el cual es definido como un trabajo. Implica además cumplir rigurosamente con el Código Ético del Hampa. 2) No Sapear, es decir, no delatar. La delación tiene graves sanciones y es considerado uno de los peores delitos. 3) Robarles a los Ricos. Los que roban a los pobres son marginados de los estratos superiores y asignados al último estrato contracultural. 4) Respetar la Familia del Ladrón. Quienes transgreden este valor sufren drásticas sanciones. 5) Tener Corazón. Implica ser valiente, lúcido (el ladrón profesional no necesita psicotrópicos para "agrandar el corazón" como los no profesionales), sereno y atinado en los momentos de peligro. 6) Tener Sentimientos. El Ladrón-Ladrón es una persona especialmente afectiva y solidaria con su clase de pertenencia y con los compañeros o "machucaos" en las cárceles o en la calle (El término "machucao" recuerda el infortunio de los marginales). 7) Ser Correcto. Ser correcto es ser de una sola palabra (los de estrato superior no necesitan dar la palabra de hombre o de honor) respetuoso y automarginarse de rencillas de poca monta. 8) Hacerse Respetar. Un Ladrón profesional debe hacerse respetar aunque en ello vaya su vida. 9) Ser de una Línea. El Ladrón Profesional es correcto, no traiciona, es justo y sabe cumplir sus compromisos. No cambia sus valores. 10) No hacer daño innecesario. Se trata de ser Ladrón Profesional. Como se ha señalado el hampa se siente profundamente preocupado por este nuevo tipo emergente de Delincuencia no Profesional que ocasiona daños innecesarios. 11) No cometer delitos sexuales en el medio libre. La persona que comete Delitos Sexuales jamás podrá integrarse al hampa. Quien comete Delitos Sexuales no es Ladrón.

Dado que las Cárceles son definidas contraculturalmente como "de los Ladrones", los jóvenes y adultos ladrones-ladrones y no ladrones forman parte de la estructura informal-formal de las Unidades y participan de la normatividad contracultural y de los beneficios contraculturales de ese sistema.

Los jóvenes Delincuentes no Profesionales, correspondientes a los Ocasionales (obreros que roban ocasionalmente debido a la baja remuneración que les impide sobrevivir) o a los Choros de esquina, y que son considerados "giles", hermosos (o "joyas blancas") y "débiles de mente" (psicología del hampa que alude a mentes de fácil dominio), o aquéllos que han cometido un "error" (Delito contracultural tipificado como tal en cl Código Penal del Hampa -especialmente 
el "sapeo"- o los Delitos sexuales) suelen ser utilizados sexualmente de "caballos", transformándose las cárceles en verdaderos centros de incubación del SIDA.

Los roles sexuales intrapenitenciarios en la subcultura carcelaria son objetivados por individuos que son "maricones netos" o "caballos". Los caballos son "fabricados" mediante violaciones masivas y posteriormente utilizados por una "carreta" (grupo primario base) o por un solo interno con suficiente cartel o sometido a una larga condena o a perpetuo.

La existencia de un Reglamento Carcelario de carácter eminentemente punitivo y obsoleto (de 1928), que desconoce la existencia del Instinto Sexual y prohíbe las relaciones heterosexuales en el marco de los Venusterios o Visitas Conyugales, ha hecho surgir en las Unidades Penales formas de satisfacción sexual alternativas.

De esta forma, se distinguen estos dos tipos de roles fundamentales destinados a satisfacer sexualmente a la Población Penal. Los sujetos que cumplen estos roles son eminentemente jóvenes y corresponden, como se señaló, a "los homosexuales o maricones netos" (por genética) quienes suelen constituir parejas estables en los centros de reclusión en términos voluntarios y "los caballos", que por el drama que reviste su existencia cotidiana requieren de una urgente atención por parte de los Organismos Nacionales destinados a implementar las Políticas de Rehabilitación o de Habilitación (Ávila J. 1991) y de los Organismos Internacionales destinados a salvaguardar los Derechos Humanos, resultando evidente en este plano la solución Política: el reconocimiento de la existencia de los Instintos Sexuales y la implementación de Venusterios.

El rol de "caballo" es desempeñado en forma obligatoria y frecuentemente bajo amenaza de muerte, preferentemente por muchos jóvenes no delincuentes, de forma que en la actualidad estar condenado a la pérdida de la libertad, implica en gran medida encontrarse además condenado a muerte dada la potencialidad creciente de contraer el Virus del SIDA.

Se proponen Políticas Diferenciales de Prevención y de Rehabilitación para los distintos Tipos de Delincuencia y en particular para la Delincuencia Masculina Juvenil Profesional Contracultural y para la Delincuencia Masculina no Profesional Urbana (Cooper D. 1992).

La exclusiva utilización de la Represión, sólo genera más cárceles. Un conocimiento etiologico profundo de los distintos tipos de delincuencia y un conocimiento exhaustivo de las manifestaciones contraculturales delictuales, en cambio, posibilitan la revisión de las actuales Políticas de Prevención y Rehabilitación, así como la elaboración de nuevas Políticas y Programas de amplia cobertura en distintos niveles de análisis más atingentes a la realidad empírica de este grave problema social.

\section{BIBLIOGRAFÍA BÁSICA}

BONGER W. Introducción a la Criminología. F.C.E. 1933.

BASTIDE R. Antropología Aplicada. Anorrortu 1977.

BASTIDE R. El Prójimo y el Extraño. Amorrortu 1970.

Baratta A., Bulnes C. Criminología Crítica y Crítica del Derecho Penal. S. XXI 1982.

Berdichewski B. Los Mapuches y la Tierra. PAS 1983. Agrarian Reform in Chile and its Impacts on Araucanian Indian Comunities. U. Texas, 1977.

BERGLUND S. The National Integration of Mapuche. Umea, Sweden 1977.

BeYHA F. Cultural Contacts and Change. N. York. 1980.

COHEN A. Jóvenes Delincuentes. Free Press, 1955.

COOPER, D. Delincuencia actual en Chile y en Santiago (En prensa Ed. Andrés Bello).

Cooper D. Teoría del Continuo Cubcultural de la Delincuencia. U. de Chile, 1990.

CARDOSO y FaleTto. Dependencia y desarrollo en América Latina 1967.

Department of Jistice USA. Documentos 1980, 1981.

FRANK, G. Capitalismo y subdesarrollo en América Latina. Signo 1970.

Franco, R. Tipología de América Latina. ILPES. 1973. 


\section{REVISTA DE SOCIOLOGIA}

GLUeCK E. y S. Unraveling Juvenile Delinquency. C. Fund. 1956.

Inkeles y Smith. Becoming Modern: Individual Change in Six Developing Countries. Harvard 1974.

MANQUilef, M. Las tierras de Arauco. El Último Cacique. Imp. Univ. 1915.

MunizaGa, C. Estructuras Transicionales. U. de Chile. Notas del Centro de Estudios Antropológicos. 1961.

Rico, J. Crimen y Justicia en América Latina. S. XXI. 1981. 